\title{
Effect of the Porous Supports Properties on the Biocomposite Fertilizers Resistant to Leaching of Potassium and Phosphates
}

\author{
Evgeniya V. Veprikova, Irina V. Korolkova, \\ Nikolai V. Chesnokov and Boris N. Kuznetsov* \\ Institute of Chemistry and Chemical Technology SB RAS \\ FRC "Krasnoyarsk Science Center SB RAS" \\ 50/24 Akademgorodok, Krasnoyarsk, 660036, Russia
}

Received 26.03.2017, received in revised form 30.04.2017, accepted 07.06.2017

\begin{abstract}
Properties of the biocomposite fertilizers obtained by impregnation of porous supports of a different nature by water solution of $\mathrm{K}_{2} \mathrm{HPO}_{4}$ were studied. The influence of the supports nature (activated charcoal BAU, pine bark and pine sawdust) and preparation conditions on fertilizers resistance to leaching by water was studied. It was shown, that biocomposite fertilizers with support from pine sawdust have the largest waterproof that provides their prolonged action.
\end{abstract}

Keywords: fertilizer, phosphates, potassium, porous support, activated charcoal, pine bark, sawdust, leaching by water.

DOI: $10.17516 / 1998-2836-0020$.

(c) Siberian Federal University. All rights reserved

* Corresponding author E-mail address: inm@icct.ru 


\title{
Влияние свойств пористых подложек \\ на устойчивость биокомпозитных удобрений \\ к вымыванию калия и фосфора
}

\author{
Е.В. Веприкова, И.В. Королькова, \\ Н.В. Чесноков, Б.Н. Кузнецов \\ Институт химии и химической технологии СО РАН \\ ФИЦ «Красноярский научный иентр СО РАН» \\ Россия, 660036, Красноярск, Академгородок, 50/24
}

Исследованы свойства биокомпозитных удобрений, полученных пропиткой пористых подложек различной природы водным раствором $K_{2} \mathrm{HPO}_{4}$. Изучено влияние природы подложек (активированный уголь БАУ, кора и опилки сосны) и условий получения на устойчивость удобрений к вымыванию водой. Показано, что наибольшей водостойкостью отличаются биокомпозитные удобрения на основе подложки из опилок сосны, что обеспечивает эффект их пролонгированного действия.

Ключевые слова: удобрение, фосфаты, калий, пористая подложка, активированный уголь, кора сосны, опилки, вымывание водой.

\section{Введение}

Древесные отходы являются доступным, воспроизводимым сырьем для получения различных продуктов с востребованными свойствами [1]. Однако основная часть таких отходов сжигается или вывозится в отвалы, что служит фактором дополнительного загрязнения окружающей среды продуктами разложения биомассы. Перспективным направлением утилизации древесных отходов остается получение на их основе органических и органоминеральных удобрений [2]. Большой интерес представляет создание удобрений пролонгированного действия, способных к длительному выделению питательных элементов в почву. Такие удобрения имеют огромное значение для решения комплекса экологических проблем в аграрной области - их применение позволяет снизить уровень загрязнения грунтовых и поверхностных вод в районах активного земледелия, устранить эффект засоления почв вследствие применения традиционных видов удобрений [3].

Один из известных способов обеспечить удобрению эффект пролонгированного действия заключается в применении носителя питательных элементов. Такой носитель представляет собой пористый материал с сорбционными или ионообменными свойствами. В качестве носителей предложено использовать природные цеолиты, синтетические пористые материалы и иониты. Недостаток органических веществ в цеолитовых удобрениях может быть восполнен за счет добавки, например, торфа [4-6]. В литературе предложены различные способы получения удобрений на основе цеолита, изучены процессы сорбции и десорбции активных компонентов. Однако влияние структуры и физико-химических свойств минеральных носителей на свойства удобрений практически не рассмотрены [7-9].

$$
-227-
$$


Капиллярно-пористая структура и наличие функциональных групп разной природы делают древесные отходы перспективным сырьем для получения таких носителей. Кроме того, за счет биоразложения древесных носителей в почве происходит ее обогащение комплексом полезных органических веществ, что важно для сохранения и повышения плодородия почвы. В литературе показана возможность получения биокомпозитных удобрений пролонгированного действия на основе пористых подложек из луба и коры березы [10-12]. Удаление из коры березы полифенольных веществ, негативное влияющих на рост и развитие растений, происходит в результате обработки исходного сырья 1,5\%-м водным раствором щелочи. Одновременно развивается пористая структура подложки. Древесные отходы в зависимости от своей природы имеют различное анатомическое строение и физико-химические свойства, которые определяют способность пористых носителей удерживать нанесенные активные компоненты. Поэтому изучение свойств удобрений, получаемых на основе различных древесных отходов, является актуальной задачей.

Цель данной работы заключалась в изучении устойчивости биокомпозитных удобрений, полученных пропиткой подложек различной природы раствором $\mathrm{K}_{2} \mathrm{HPO}_{4}$, к вымыванию фосфатов и калия водой.

\section{Экспериментальная часть}

Биокомпозитные удобрения получали на основе пористых подложек (ПП) из коры сосны, древесины сосны и активированного угля марки БАУ-А.

Воздушно-сухое (влажность 11,8 $\pm 0,5$ \%) древесное сырье измельчали на дезинтеграторе марки "Nossen" (Германия) и для получения ПП отбирали образцы коры или опилок следующего фракционного состава, мас. \%: $(0,25-0,50)$ мм - 23,7; $(0,50-1,00)$ мм - 76,3.

Подложку из коры и подложку из опилок сосны получали обработкой исходного сырья 1,5\%-м водным раствором $\mathrm{NaOH}$ при гидромодуле, равном 10 , температуре $90{ }^{\circ} \mathrm{C}$ в течение 1 ч и перемешивании. Стадии промывок ПП водой и нейтрализации остатков щелочи проводили аналогично методике, приведенной в работе [13]. Значение гидромодуля на этих стадиях равнялось 8 . Полученные древесные подложки сушили при $(50 \pm 5)^{\circ} \mathrm{C}$ до воздушно-сухого состояния.

Для приготовления ПП зерненный активированный уголь БАУ измельчали и готовили смесь вышеуказанного фракционного состава. Биокомпозитные удобрения получали на основе измельченного угля и модифицированного образца БАУ ${ }^{1}$. Образец БАУ ${ }^{1}$ был получен обработкой исходного угля БАУ $0,15 \mathrm{~N}$ раствором $\mathrm{HNO}_{3}$ при температуре $90{ }^{\circ} \mathrm{C}$ в течение 8 ч. Затем образец был отмыт от остатков кислоты дистиллированной водой.

Получение биокомпозитных удобрений (БУ) включает следующие стадии: пропитку подложек водным раствором $\mathrm{K}_{2} \mathrm{HPO}_{4} \times 3 \mathrm{H}_{2} \mathrm{O}$; сушку пропитанных подложек; дополнительную обработку образцов БУ раствором кислоты и их сушку при $(95 \pm 5){ }^{\circ} \mathrm{C}$. На подложки наносили 25,8 мас. \% соли, что обеспечивало содержание фосфора и калия в образцах БУ в количестве 3,5 и 8,9 мас. \% соответственно. Температуру сушки образцов БУ варьировали от 60 до $200{ }^{\circ} \mathrm{C}$. Условия стадий пропитки ПП раствором соли и обработки образцов удобрений растворами $0,05-0,25 \mathrm{~N}$ азотной кислоты соответствовали методике работы [12].

Предельный объем пор $\mathrm{W}_{\mathrm{S}}\left(\mathrm{cm}^{3} / \Gamma\right)$ определяли по сорбции паров бензола в статических условиях по методике [14]. Суммарный объем пор $\mathrm{V} \sum\left(\mathrm{cm}^{3} / \Gamma\right)$ был определен согласно методике 
ГОСТ 8858-93. Удельную поверхность $\mathrm{S}_{\text {уд }}$ ( $\left.{ }^{2} / \Gamma\right)$ устанавливали методом низкотемпературной адсорбции азота на анализаторе «Сорбтометр - М».

Влагоемкость (ВЛ) подложек оценивали по методике ГОСТ 24160-80. Определение в древесных подложках остаточного количества веществ $\left(\mathrm{BP}_{\mathrm{NaOH}}\right)$, растворимых в $1 \% \mathrm{NaOH}$, выполняли по общепринятой в химии древесины методике [15].

Вымывание фосфатов и калия водой проводили в стационарных условиях дистиллированной водой при комнатной температуре. Соотношение образцов БУ и воды составляло 1,5 г к 250 мл. Продолжительность вымывания варьировали от 15 мин до 8 сут. В длительных экспериментах каждые 24 ч проводили замену раствора свежей порцией (250 мл) воды. Концентрацию фосфора в воде определяли методом масс-спектрометрии (ICP-MS 7500 Agilent), а концентрацию калия - атомно-эмиссионным методом (Analyst-400).

Устойчивость получаемых удобрений к вымыванию водой оценивали по остаточному содержанию в них фосфора и калия (\%, в пересчете на $\mathrm{P}_{2} \mathrm{O}_{5}$ и $\left.\mathrm{K}_{2} \mathrm{O}\right)$. При расчетах исходные количества исследуемых компонентов в образцах БУ принимались за $100 \%$.

Электронно-микроскопическое исследование пористых подложек проводили на электронном растровом микроскопе ТМ - 1000 (НITACHI, Япония).

Регистрацию ИК-спектров образцов подложек и БУ осуществляли на ИК-Фурье спектрометре Tensor-27 (Bruker, Германия) в области 4000-400 см-1. Обработку спектральной информации проводили с помощью пакета программ OPUS, версия 5.5. Образцы для получения ИК-спектров готовили в виде таблеток в матрице бромистого калия при одинаковых условиях. Навеска исследуемых материалов составляла 5 мг на 1 г бромистого калия.

\section{Результаты и обсуждение}

Установлено, что получаемые в результате щелочной обработки подложки из коры и опилок сосны по значениям предельного сорбционного объема пор $\left(\mathrm{W}_{\mathrm{s}}\right)$ и площади удельной $\left(\mathrm{S}_{\mathrm{y}}\right)$ поверхности существенно уступают подложкам на основе БАУ, но обладают большей влагоемкостью (табл. 1).

Наблюдаемые различия обусловлены различиями текстуры подложек и различной способностью к смачиванию водой.

Следует отметить, что обработка коры и опилок сосны водным раствором щелочи проводится в достаточно мягких условиях - концентрация $\mathrm{NaOH}$ составляет 1,5 \%, температура обработки $90{ }^{\circ} \mathrm{C}$. Это позволяет сохранить у получаемых подложек специфическую капиллярно-пористую структуру прекурсоров. Очевидно, наблюдаемые различия во влаго-

Таблица 1. Свойства пористых подложек (ПП), применяемых для получения биокомпозитных удобрений

\begin{tabular}{|c|c|c|c|c|}
\hline Материал ПП & $\mathrm{W}_{\mathrm{s}}, \mathrm{cm}^{3} / \Gamma$ & $\mathrm{S}_{\mathrm{yд}}, \mathrm{M}^{2} / \Gamma$ & $\mathrm{BЛ,} / \Gamma$ & $\mathrm{BP}_{\text {NaOH }}, \%$ \\
\hline Кора сосны & 0,031 & 2,36 & 2,69 & 26,28 \\
\hline Опилки сосны & 0,028 & 2,12 & 3,49 & 8,95 \\
\hline БАУ & 0,310 & 524,6 & 1,43 & нет \\
\hline БАУ 1 & 0,318 & 530,2 & 2,17 & нет \\
\hline
\end{tabular}


емкости ПП из коры и опилок обусловлены разным анатомическим строением древесного сырья.

Электронно-микроскопические снимки показывают, что текстура подложки из коры представлена преимущественно крупными порами и полостями с размером от 5 до 45 мкм. На отдельных участках поверхности хорошо видны мелкие поры (так называемые ситовые поля [16]) размером 1,2-2,5 мкм (рис. 1-1).

На поверхности ПП из опилок также можно выделить фрагменты с многочисленными порами размером от 1,3 до 2,9 мкм (рис. 1-2). Очевидно, эти участки представляют собой стенки трахеид, разрушенных в процессе измельчения древесной щепы. Средний диаметр трахеид, на долю которых в древесине сосны приходится до 93,1 \%, варьируется от 10 до 50 мкм. При этом их длинах колеблется от 1,4 до 4,4 мм [16]. Присутствие в ПП из коры и опилок мелких пор может способствовать более равномерному распределению $\mathrm{K}_{2} \mathrm{HPO}_{4}$ при пропитке подложек раствором соли.

Подложки из активированного угля БАУ и БАУ ${ }^{1}$ имеют развитую систему микро- и мезопор, о чем свидетельствуют значения предельного сорбционного объема $\mathrm{W}_{\mathrm{s}}$ (сумма микро- и мезопор [14]) (табл. 1). Известно, что БАУ содержит значительно больше микропор по сравнению с мезопорами - Vмикр $0,20-0,25 \mathrm{~cm}^{3} / \Gamma$, а Vмезо $0,08-0,10 \mathrm{~cm}^{3} / \Gamma$ [17]. Было установлено, что суммарный объем пор $\mathrm{V} \sum$ образцов БАУ и БАУ ${ }^{1}$ составляет 1,31 и $1,39 \mathrm{~cm}^{3} / \Gamma$ соответственно. Сравнение значений $\mathrm{V} \sum$ и $\mathrm{W}_{\mathrm{s}}$ показывает, что на долю макропор в структуре подложек на основе активированного угля приходится 76 - 77 \%. Из-за особенностей пористой структуры БАУ был выбран для сравнения с древесными подложками, поскольку, как известно, высокая микропористость активных углей ограничивает их применение для получения нанесенных композитов [18].

Также эффективность активных углей в качестве подложек для нанесения различных компонентов осложняется гидрофобностью их поверхности. Для повышения смачиваемости углеродных материалов их обрабатывают растворами кислот [18]. Так, обработка БАУ раствором азотной кислоты привела к увеличению влагоемкости модифицированного образца БАУ' в 1,5 раза по сравнению с исходным БАУ (табл. 1).

Однако несмотря на развитую пористую структуру и высокое значение влагоемкости подложки БАУํㅡㄹ образцы удобрений на ее основе характеризуются низкой устойчивостью к вымы-
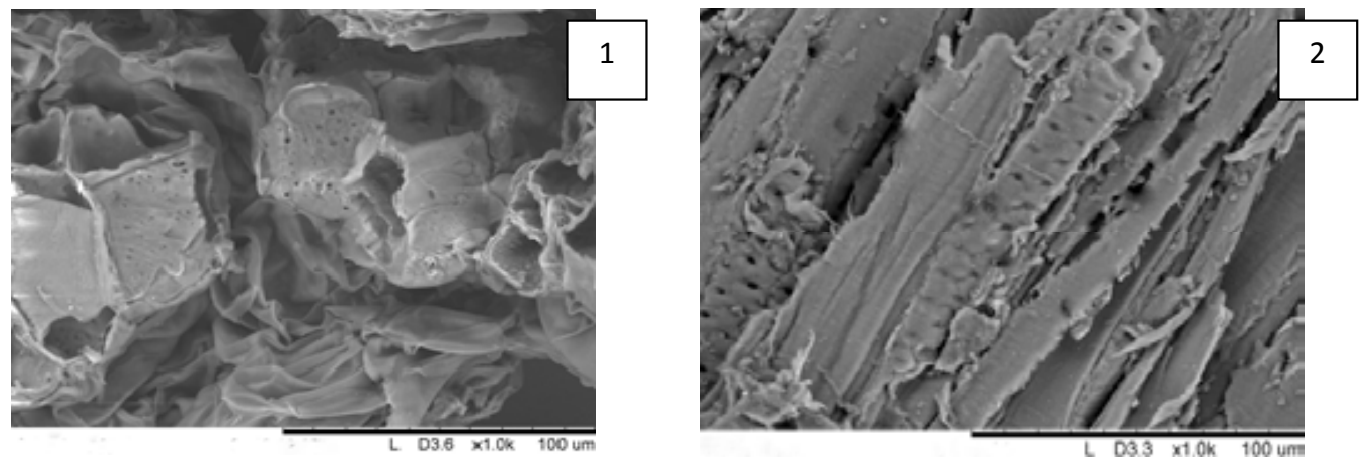

Рис. 1. Электронно-микроскопические снимки пористых подложек из коры (1) и опилок (2) сосны 
ванию активных компонентов. При этом подложки из активированного угля, независимо от их влагоемкости, мало отличаются по способности удерживать фосфаты и калий (табл. 2).

Удобрения на основе БАУ, БАУํㅡ и подложки из коры сосны, температура сушки которых не превышает $100^{\circ} \mathrm{C}$, мало отличаются по своей устойчивости к вымыванию фосфатов водой. Различие проявляется только при повышении температуры до $200{ }^{\circ} \mathrm{C}$ - образец БУ на основе коры превосходит БУ на основе активного угля в 1,4 раза. Подложки из активированного угля хуже удерживают калий по сравнению с ПП из коры и ПП из опилок сосны независимо от температуры сушки удобрений (табл. 2).

Установлено, что из образцов БУ на основе подложки из опилок водой вымывается существенно меньше фосфатов и калия по сравнению с образцами БУ на основе подложки из коры сосны. При сопоставлении данных табл. 1 и 2 можно выявить зависимость устойчивости БУ к вымыванию активных компонентов водой от влагоемкости древесных подложек. Вероятно, благодаря высокой влагоемкости подложки из опилок происходит более равномерное распределение соли в процессе пропитки раствором $\mathrm{K}_{2} \mathrm{HPO}_{4}$. Это способствует уменьшению вымывания активных компонентов водой.

По данным табл. 2 видно, что природа подложек влияет на их способность удерживать калий и фосфаты. Подложки из коры сосны, БАУ и БАУํㅛㄹу удерживают калий по сравнению с фосфатами независимо от температуры высушивания БУ. В случае подложки из опилок различие в вымывании фосфатов и калия наблюдается только для образца БУ, высушенного при $200{ }^{\circ} \mathrm{C},-$ он лучше удерживает фосфаты. Можно предположить, что благодаря электростатическому взаимодействию и сорбции калий лучше закрепляется на поверхности подложек из коры и активного угля [19].

Установлено, что от природы подложек зависит характер влияния температуры сушки удобрений на их водостойкость. Так, повышение температуры мало влияет на вымывание ка-

Таблица 2. Устойчивость биокомпозитных удобрений (БУ) на основе различных пористых подложек (ПП) к вымыванию фосфатов и калия водой (продолжительность вымывания 15 мин)

\begin{tabular}{|c|c|c|c|}
\hline Материал ПП & $\begin{array}{c}\text { Температура сушки } \\
\text { БУ, }{ }^{\circ} \mathrm{C}\end{array}$ & $\begin{array}{c}\text { Устойчивость } \\
\text { к вымыванию фосфатов } \\
\text { из БУ, \%* }\end{array}$ & $\begin{array}{c}\text { Устойчивость } \\
\text { к вымыванию калия } \\
\text { из БУ, \%* }\end{array}$ \\
\hline \multirow{2}{*}{ БАУ } & 60 & 12,2 & 37,9 \\
& 100 & 14,4 & 39,0 \\
& 200 & 37,1 & 49,7 \\
\hline \multirow{2}{*}{ БАУ } & 60 & 12,5 & 38,6 \\
& 100 & 14,5 & 39,6 \\
\hline \multirow{2}{*}{ Кора сосны } & 200 & 37,8 & 44,3 \\
& 60 & 12,9 & 47,4 \\
Опилки сосны & 100 & 17,1 & 60,2 \\
\hline & 200 & 53,2 & 72,3 \\
& 100 & 73,2 & 73,3 \\
\hline
\end{tabular}

* \% от исходного содержания фосфатов и калия в удобрении; БУ получены без дополнительной обработки кислотой. 
лия из БУ на основе подложки из опилок сосны. Изменение температуры сушки подложки из коры сосны и БАУ 1 , пропитанных раствором соли, от 100 до $200{ }^{\circ} \mathrm{C}$ приводит к увеличению устойчивости получаемых БУ к вымыванию калия в 1,3 раза. При этом для таких удобрений достигается существенно большее увеличение устойчивости к вымыванию фосфатов - в 3,1 раза для БУ на основе коры и в 2,6 раза для БУ на основе БАУ‥ Увеличение водостойкости образца БУ на основе подложки из опилок по фосфатам в аналогичных условиях существенно меньше и составляет 8,4 \% (табл. 2).

Известно, что повышение температуры сушки сопровождается изменениями динамики фронта испарения, что способствует более равномерному распределению активных компонентов в пористом носителе [18]. При изучении свойств биокомпозиционных удобрений на основе коры березы, полученных пропиткой растворами гидрофосфата калия, было отмечено влияние взаимодействия органических веществ древесных подложек и соли на их водостойкость [12].

Отличительная особенность подложек из коры и опилок сосны - присутствие в них веществ, способных растворяться в щелочном реагенте, например в $1 \% \mathrm{NaOH}$ (табл. 1). Типичным щелочным реагентом является и соль $\mathrm{K}_{2} \mathrm{HPO}_{4}$, раствор которой применялся для получения биокомпозитных удобрений. Можно предположить, что вещества, образующиеся в результате пропитки подложек раствором соли и их нагревании до $200{ }^{\circ} \mathrm{C}$ в процессе сушки, заполняют поры подложек и препятствуют вымыванию активных компонентов водой. Рис. 2 иллюстрирует изменения морфологии поверхности подложки из коры сосны, произошедшие за счет ее пропитки раствором соли и сушки при $200{ }^{\circ} \mathrm{C}$. Очевидно, что в результате движения фронта испарения вещества, образовавшиеся при пропитке, выносятся на внешнюю поверхность пор и полостей подложки, частично или полностью закрывая вход в них.

Различия в водостойкости БУ на основе подложки из коры и подложки из опилок сосны, полученных при температуре сушки $200{ }^{\circ} \mathrm{C}$, коррелируют с содержанием в них веществ, растворимых щелочью $\mathrm{BP}_{\mathrm{NaOH}}$. Чем больше подложка содержит таких веществ, тем больше достигаемый позитивный эффект. Однако независимо от условий подложка из опилок существенно лучше удерживает фосфаты и калий (табл. 1 и 2).

Из анализа приведенных ИК-спектров (рис. 3) следует, что пропитка пористой подложки из опилок сосны (кривая 1) раствором $\mathrm{K}_{2} \mathrm{HPO}_{4}$ вызывает появление в спектре биокомпозит-

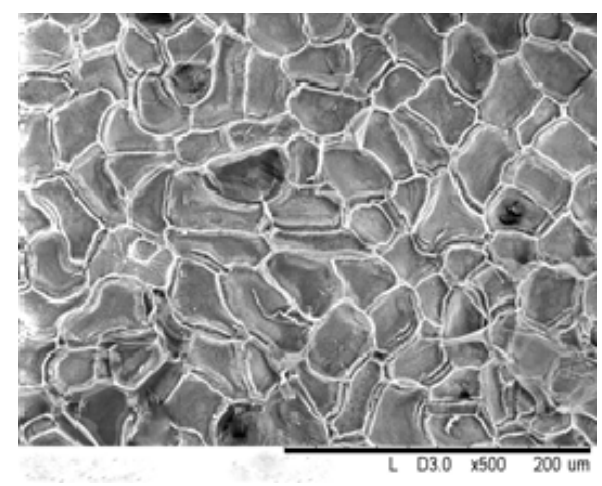

Рис. 2. Электронно-микроскопический снимок поверхности биокомпозитного удобрения на основе подложки из коры сосны $\left(25,8\right.$ мас. \% K2HРО4, температура сушки $\left.200{ }^{\circ} \mathrm{C}\right)$ Увеличение в 500 раз 


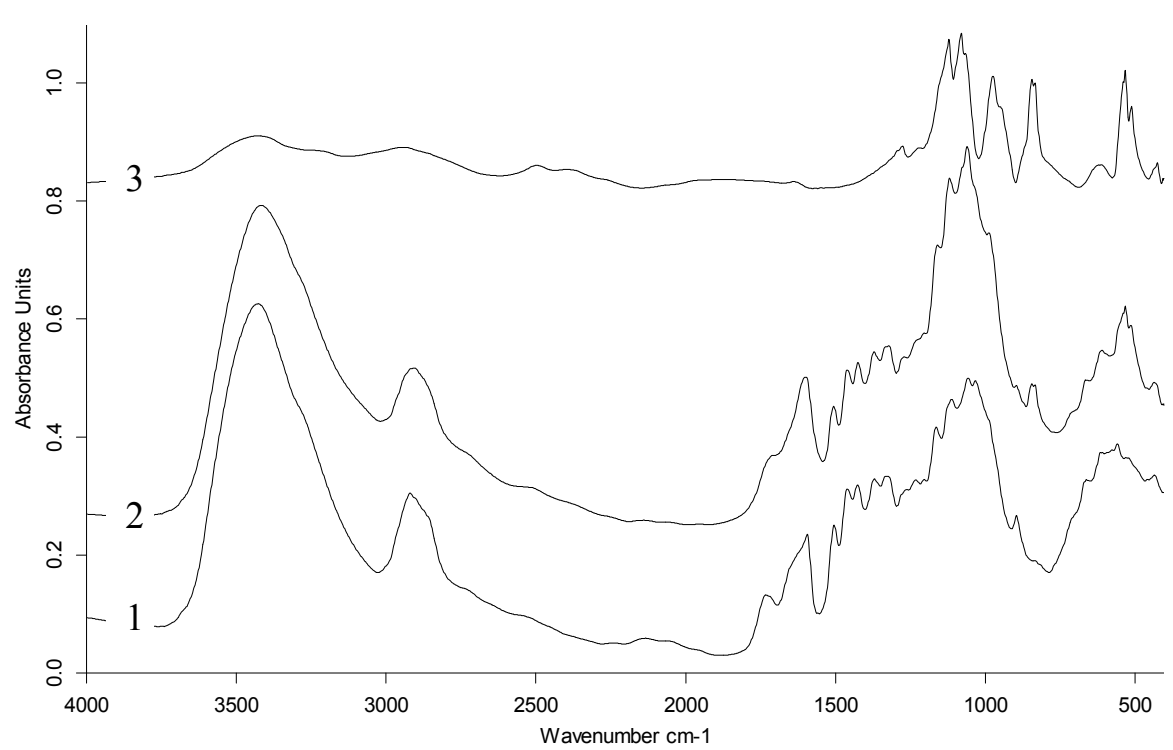

Рис. 3. ИК-спектры пористой подложки из опилок сосны и биокомпозитного удобрения (БУ) на ее основе (температура сушки $\left.200^{\circ} \mathrm{C}\right): 1$ - ИК-спектр пористой подложки, 2 - ИК-спектр БУ, 3 - ИК-спектр $\mathrm{K}_{2} \mathrm{HPO}_{4} \times 3 \mathrm{H}_{2} \mathrm{O}$

ного удобрения (кривая 2) новых полос поглощения при 1061, 846 и 533 см$^{-1}$, относяшихся к колебаниям отдельных структурных элементов $\mathrm{K}_{2} \mathrm{HPO}_{4}$ (кривая 3) [20]. При этом сдвига характеристических полос поглощения, соответствующих различным функциональным группам подложки, после нанесения соли не происходит. Очевидно, это может свидетельствовать о физической сорбции $\mathrm{K}_{2} \mathrm{HPO}_{4}$ пористой подложкой из опилок сосны.

Аналогичная спектральная картина наблюдается и для пористой подложки из коры сосны и БУ на ее основе (рис. 4).

Можно предположить, что на формирование водостойкости биокомпозитных удобрений очень влияют и особенности капиллярно-пористых структур подложек из коры и опилок сосны.

Помимо увеличения водостойкости образцов БУ на основе ПП из коры и ПП из опилок отмечено появление окрашивания водных растворов после контакта с удобрениями - более интенсивного (в среднем в 2,3 раза) для БУ на основе коры. Появление окраски вызвано увеличением доли водорастворимых веществ в получаемых удобрениях.

Известно, что эффективным приемом уменьшения окраски водных вымывов и повышения водостойкости биокомпозитных удобрений на основе луба и коры березы является обработка разбавленным раствором кислоты [12].

Подобная обработка также оказывает позитивное влияние на устойчивость удобрений на основе подложек из коры и опилок сосны к вымыванию активных компонентов водой (табл. 3).

Установлено, что концентрация раствора $\mathrm{HNO}_{3}$ для обработки образцов БУ, которая обеспечивает максимальное уменьшение вымывания фосфатов и калия водой, зависит от содержания в подложках щелочерастворимых веществ $\mathrm{BP}_{\mathrm{NaOH}}$. Сравнение показывает, чем меньше подложка содержит $\mathrm{BP}_{\mathrm{NaOH}}$, тем при меньшей концентрации кислоты достигается наибольший эффект (табл. 1 и 3). Обработка кислотой приводит, очевидно, к осаждению веществ, образую- 


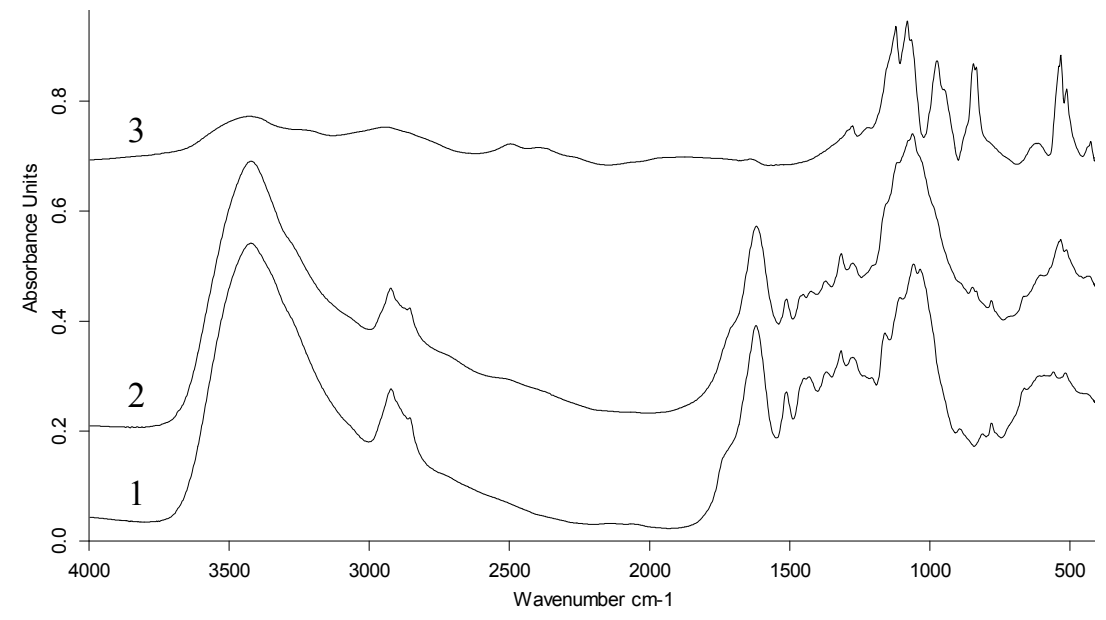

Рис. 4. ИК-спектры пористой подложки из коры сосны и биокомпозитного удобрения (БУ) на ее основе (температура сушки $200{ }^{\circ} \mathrm{C}$ ): 1 - ИК-спектр пористой подложки, 2 - ИК-спектр БУ, 3 - ИК-спектр $\mathrm{K}_{2} \mathrm{HPO}_{4} \times 3 \mathrm{H}_{2} \mathrm{O}$

Таблица 3. Влияние концентрации кислоты на вымывание активных компонентов из биокомпозитных удобрений (БУ) на основе различных пористых подложек (ПП)

\begin{tabular}{|c|c|c|c|}
\hline Материал ПП & Концентрация $\mathrm{HNO}_{3}, \mathrm{~N}$ & $\begin{array}{c}\text { Устойчивость к } \\
\text { вымыванию фосфатов } \\
\text { из БУ, \%* }\end{array}$ & $\begin{array}{c}\text { Устойчивость } \\
\text { к вымыванию калия } \\
\text { из БУ, \%* }\end{array}$ \\
\hline \multirow{2}{*}{ Кора сосны } & 0 & 53,2 & 60,2 \\
& 0,05 & 57,6 & 63,6 \\
& 0,10 & 70,8 & 68,7 \\
\hline \multirow{2}{*}{ Опилки сосны } & 0,25 & 87,4 & 75,7 \\
\hline \multirow{2}{*}{ БАУ } & 0 & 83,3 & 82,2 \\
& 0,05 & 91,9 & 87,8 \\
& 0,10 & 94,9 & 84,1 \\
\hline & 0,25 & 94,7 & 51,3 \\
& 0,10 & 37,8 & 44,4 \\
\hline
\end{tabular}

* от исходного содержания фосфатов и калия в удобрении; образцы БУ высушены при 200 으.

щихся в древесных подложках в результате пропитки гидрофосфатом калия, что создает дополнительные внутридиффузионные затруднения вымыванию водой активных компонентов из получаемых биокомпозитных удобрений.

В образцах БУ на основе активированного угля БАУ 1 дополнительная обработка растворами кислоты ведет к уменьшению устойчивости к вымыванию фосфатов и калия водой. Возможная причина наблюдаемого факта заключается в изменении характера электростатического взаимодействия поверхности подложки с гидрофосфатом калия [19].

Установлено, что удобрения на основе подложки из опилок и подложки из коры способны к медленному вымыванию фосфатов и калия в течение длительного времени. При этом 


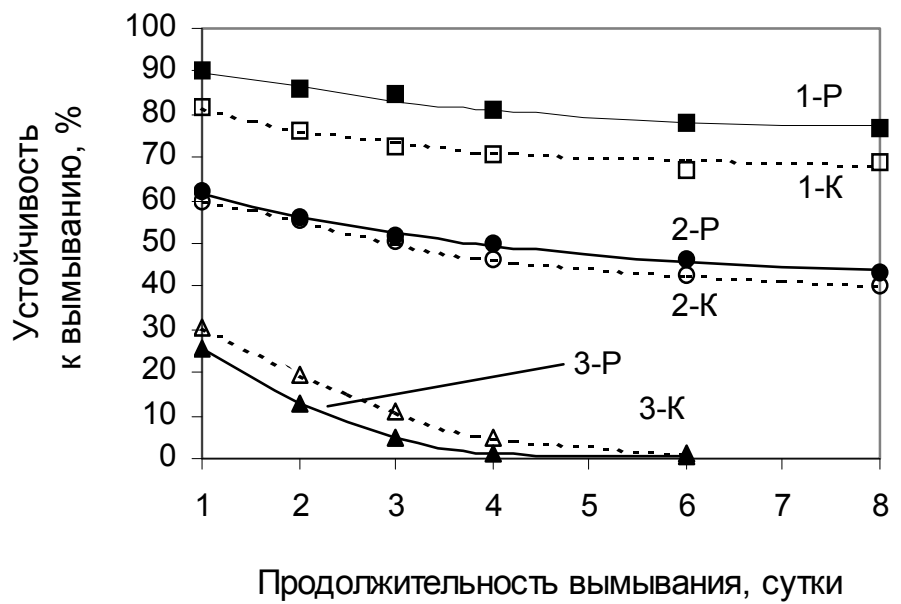

Рис. 5. Вымывание фосфатов (1-Р, 2-Р, 3-Р) и калия (1-К, 2-К, 3-К) водой из биокомпозитных удобрений на основе опилок (1) и коры (2) сосны и БАУ ${ }^{1}$ (3)

наибольшей водостойкостью характеризуется удобрение на основе опилок. Образец на основе активированного угля существенно уступает по своей водостойкости удобрениям на основе древесных подложек - через 4 сут из него вымывается 98,8 \% фосфатов и 95,3 \% калия (от исходного содержания компонентов в БУ) (рис. 5). Исследуемые образцы БУ после нанесения соли были высушены при $200{ }^{\circ} \mathrm{C}$, а образцы на основе опилок и коры дополнительно обработаны $0,1 \mathrm{~N}$ раствором кислоты.

Было выявлено, что образец удобрения на основе подложки из сосновых опилок, высушенный после пропитки гидрофосфатом калия при $100{ }^{\circ} \mathrm{C}$ без последующей обработки кислотой, также характеризуется высокой устойчивостью к вымыванию активных компонентов водой - через 8 сут в нем остается 53,2 \% фосфатов и $52,1 \%$ калия. Такой образец по своей водостойкости превосходит БУ на основе коры, полученный при температуре сушки $200{ }^{\circ} \mathrm{C}$ и дополнительной обработке $0,1 \mathrm{~N}$ раствором кислоты, в среднем на 10 \%.

Наблюдаемый характер вымывания фосфатов и калия из биокомпозитных удобрений, получаемых на основе подложек из коры и опилок сосны, свидетельствует об эффекте их пролонгированного действия.

\section{Заключение}

В результате изучения свойств биокомпозитных удобрений, полученных пропиткой пористых подложек различной природы водным раствором $\mathrm{K}_{2} \mathrm{HPO}_{4}$, выявлено влияние текстуры и физико-химических свойств подложек на устойчивость удобрений к вымыванию водой фосфатов и калия.

Установлено, что удобрения на основе подложек из активированного угля БАУ, несмотря на их развитую пористую структуру, по своей водостойкости уступают биокомпозитным удобрениям на основе подложки из коры и подложки из опилок сосны.

Определены условия получения удобрений на основе древесных подложек, обеспечивающие максимальную устойчивость к вымыванию активных компонентов: температура сушки 
$200{ }^{\circ} \mathrm{C}$; последующая пропитка удобрений на основе опилок $0,1 \mathrm{~N}$ раствором $\mathrm{HNO}_{3}$, а удобрений на основе коры сосны - 0,25 N раствором кислоты.

Установлено, что применение подложки из опилок позволяет получать биокомпозитные удобрения с наибольшей устойчивостью к вымыванию фосфатов и калия независимо от условий их приготовления. Опилки сосны по сравнению с корой являются более перспективным сырьем для получения подложек, поскольку удобрения на их основе с высокой водостойкостью могут производится в более простых условиях.

Показано, что удобрения на основе коры или опилок способны к медленному вымыванию фосфатов и калия водой - через 8 сут в них остается дне менее 43 \% фосфатов и $40 \%$ калия. Это обеспечивает эффект пролонгированного действия разработанных удобрений.

\section{Благодарности}

В работе использованы приборы центра коллективного пользования Федерального исследовательского центра «Красноярский научный центр СО РАН».

\section{Список литературы}

1. Кузнецов Б.Н., Левданский В.А., Кузнецова С.А. Химические продукты из древесной коры. Красноярск: Сиб. федер. ун-т, 2012. 260 с. [Kuznetsov B. N., Levdanskiy V.A., Kuznetsova S.A. Chemical products of woody-crust. Krasnoyarsk: Siberian Federal University, 2012. 260 p. (in Russ.)]

2. Беловежец Л.А., Волчатова И.В., Медведева С.А. Перспективные способы переработки вторичного лигноцеллюлозного сырья. Химия растительного сырья 2010. № 2, С. 5-16. [Belovejest L.A., Volchatova I.V., Medvedeva S.A. The promising methods of recoverable lignocellulosic materials processing. Chemistry of plant raw materials 2010. No. 2, P. 5-16. (in Russ.)]

3. Trenkel M.E. Slow- and Controlled - releast and stabilized Fertilizers: An option for Ebhancing Nutrient Use Efficiency in Agriculture. Second edition. Paris, 2010. 160 p.

4. Патент 2502713 РФ. Кожевникова Н.М Торфоцеолитовое удобрение пролонгированного действия, модифицированное фосфатом калия. Опубл. 27.12.2013. [Patent 2502713 RU. Kojevnikova N.M. The peat -zeolite fertilizer of long - time action modified by potassium phosphate. Publ. Date 27.12.2013 (in Russ.)]

5. Патент 2557432 РФ. Кожевникова Н.М. Торфоцеолитовое удобрение пролонгированного действия, модифицированное иодидом калия. Опубл. 20.07.2015. [Patent 2557432 RU. Kojevnikova N.M. The peat -zeolite fertilizer of long - time action modified by potassium iodide. Publ. Date 20.07.2015 (in Russ.)]

6. Заявка 2003136661 РФ. Бердников И.А., Серов К.О. Комплексное удобрение пролонгированного действия с заданными свойствами. Опубл. 20.05.2005 [The claim of an invention 2003136661 RU. Complex fertilizer of long - time action with defined properties. Publ. Date 20.05.2005 (in Russ.)]]

7. Окуджава Н.Г., Беруашвили Ц.А., Мамукошвили Н.Ш. Получение обогащенного калием природного цеолита двухтемпературным ионообменным методом с использованием морской воды. Сорбиионные и хроматографические процессы 2008. Т. 8 (5), C. 875-880. [Okudjava N.G., Beruashvily C.A., Mamukoshvily N.S. Production of enrich natural zeolite with potassium by too 
temperature ion-exchanging method with use a sea water. Sorption and chromatographic process 2008. V. 8 (5), P. 875-880. (in Russ.)]

8. Кожевникова Н.М., Абашева Н.Е., Гаркушева Н.М., Маркушева М.Г., Солдатова 3.А. Получение неодимсодержащих микроудобрений по сорбционной технологии. Химия в инmересах устойчивого развития 2005. Т. 13 (1), C. 65-69. [Kojevnikova N.M., Abasheva N.E., Garkusheva N.M., Markusheva M.G., Soldatova S.A. Production of neodymium contained micro fertilizers with sorption technology. Chemistry for Sustainable Development 2005. V. 13 (1), P. 65-69. (in Russ.)]

9. Кожевникова Н.М., Абашева Н.Е., Зонхоева Э.Л., Митыпов Б.Б., Меркушева М.Г. Физико-химические основы получения лантансодержащих микроудобрений. Химия в инmересах устойчивого развития 1999. Т. 7(6), С. 675-679. [Kojevnikova N.M., Abasheva N.E., Zonkhoeva E.L.,Mitipova B.B., Merkushtva M.G. The physicochemical basis of production of lanthanum contained micro fertilizers. Chemistry for Sustainable Development 1999. V. 7(6), P. 675679. (in Russ.)]

10. Кузнецова С.А., Кузнецов Б.Н., Скурыдина Е.С., Максимов Н.Г., Калачева Г.С., Ульянова О.А., Скворцова Г.П. Синтез и свойства биокомпозитных удобрений на основе мочевины и коры березы. Журнал Сибирского федерального университета. Химия 2013. Т. 6 (4), C. 380-393. [Kuznetsova S.A., Kuznetsov B.N., Skurydina E.S., Maksimov N.G., Kalachova G.S, Ulyanova O.A., Skvortsova C.P. Synthesis and properties of biocomposite fertilizers on the basis of urea and birch bark. Journal of Siberian Federal University. Chemistry 2013. V. 6 (4), P. 380-393. (in Russ.)]

11. Веприкова Е.В., Кузнецова С.А., Чесноков Н.В., Кузнецов Б.Н. Изучение вымывания КСl водой из биокомпозитных удобрений на основе коры березы Журнал Сибирского федерального университета. Химия 2015. T. 8 (1). C. 25-34. [Veprikova E.V., Kuznetsova S.A., Chesnokov N.V., Kuznetsov B.N. Study of KCl Leaching by water from Biocomposite Fertilizers Based on Birch Bark. Journal of Siberian Federal University. Chemistry 2015. V. 8 (1), P. 25-34. (in Russ.)]

12. Веприкова Е.В., Кузнецова С.А., Чесноков Н.В., Кузнецов Б.Н. Получение и свойства фосфорных биокомпозитных удобрений на основе коры березы. Журнал Сибирского федерального университета. Химия 2015. Т. 8 (3), C. 413-421. [Veprikova E.V., Kuznetsova S.A., Chesnokov N.V., Kuznetsov B.N. Preparation and properties of phosphorus boicomposite fertilizers based on the birch bark. Journal of Siberian Federal University. Chemistry 2015. T. 8 (3), P. 413421. (in Russ.)]

13. Веприкова Е.В., Кузнецова С.А., Чесноков Н.В., Кузнецов Б.Н. Свойства энтеросорбентов, полученных из автогидролизованной коры березы. Химия в интересах устойчивого развития 2012. T. 20 (6), С 673-678. [Veprikova E.V., Kuznetsova S.A., Chesnokov N.V., Kuznetsov B.N. Properties of enterosorbents obtained from auto hydrolyzed birch bark. Chemistry for Sustainable Development 2012. V.20 (6), P 673-678. (in Russ.)]

14. Кельцев Н.В. Основы адсорбционной техники. М.: Химия, 1976. 512 с. [Kelcev N.V. Adsorption Technology Basics. M.: Chemictry, 1976. 512 p. (in Russ.)]

15. Оболенская А.В., Ельницкая 3.П., Леонович А.А. Лабораторные работы по химиидревесины и целлюлозы. М.: Экология, 1991. 320 с. [Obolenskaya A.V., Elnitskaya Z.P., Leonovich A.A. Laboratory works on wood and cellulose chemistry. M.: Ecology, 1991. 320 p. (In Russ.)]

$$
-237-
$$


16. Фенгель Д., Вегенер Г. Древесина. Химия, ультраструктура, реакции. М.: Лесная промышленность, 1988. 512 с. [fengel D., Wegener G. Wood. Chemistry, ultrastructure, reactions. M.: Lesnaya promushlrnnost. 1988. 512 p. (in Russ.)]

17. Мухин В.М., Тарасов А.В., Клушин В.М. Активные угли России. М.: Металлургия, 2000. 352 c. [Muxin V.M., Tarasov A,V,, Klushin V.M. Active coal of Russia. M.: Metallurgya, 2000. 352 p. (in Russ.)]

18. Alvin B. Stiles Catalyst Supports and Supported Catalysts: Theoretical and Applied Concepts/ Butterworth Publishers, Stoneham, MA. 1987. 270 p.

19. Адсорбция из растворов на поверхности твердых тел: пер. с англ.; под ред. Г. Парфита, К. Рочестера. М.: Мир, 1986. 488 с. [Adsorption from Solution at the Solid Liquid Interface. Edited by G. Parfit, C. Rochester: transl. from eng. Moscow: Mir, 1986. 488 p. (in Russ.)]

20. Infrared and Raman characteristic group frequencies: Tables and charts. G. Socrates. John Wiley-Sons, 2004. 347 p. 